\title{
Políticas educacionais para a Amazônia: teorias, práticas e contradições
}

\author{
Educational policies for the Amazon: theories, practice and contradictions \\ Políticas educativas para la Amazonia: teorías, prácticas y contradicciones
}

\section{ERALDO SOUZA CARMO \\ MARIA SUELI CORRÊA PRAZERES}

\begin{abstract}
Resumo: $\mathrm{O}$ artigo discute as configurações das políticas educacionais as populações do campo na Amazônia a partir da estrutura do Estado capitalista. O método de análise está assentado nas bases do materialismo histórico dialético a fim de compreender em que medida a lógica da racionalidade econômica que impera sobre tais políticas se reflete no direito à educação destas populações. Diante disso, se evidenciou os efeitos, desafios e contradições das políticas educacionais quando partem dos órgãos centrais para realidades específicas sem o conhecimento das heterogeneidades locais.
\end{abstract}

Palavras-chave: Educação. Política. Amazônia.

\begin{abstract}
The article discusses the settings of educational policies to rural populations in Amazon, from the capitalist state structure. The method of analysis bases on the historical dialectical materialism in order to understand in what extent the logic of economic rationality that prevails on such policies reflects on the right to education of these populations. Above all, it highlights the effects, the challenges and contradictions of educational policies when departing from central bodies to specific realities without the knowledge of local heterogeneities.
\end{abstract}

Keywords: Education; Policy; Amazon.

Resumen: El artículo describe la configuración de las políticas educativas poblaciones rurales en el Amazonas desde la estructura del Estado capitalista. El método de análisis se asienta sobre la base del materialismo dialéctico histórico para comprender hasta qué medida la lógica de la racionalidad económica que impera sobre tales políticas se refleja en el derecho a la educación de estas poblaciones. Por lo tanto, se evidenció los efectos, retos y contradicciones de las políticas educativas al salir de las agencias centrales a realidades específicas sin el conocimiento de las heterogeneidades locales.

Palabras clave: Educación. Política. Amazonia. 


\section{FUNDAMENTOS E PRINCÍPIOS DAS POLÍTICAS PÚBLICAS EDUCACIONAIS}

Refletir sobre os princípios e as intencionalidades com que as políticas públicas se configuram no Estado é imprescindível para se entender a forma como são materializadas. Para tanto, é importante compreender seus significados, os sentidos e a lógica em que são pensadas. Entretanto, não se pode perder de vista que as políticas públicas mudam no interior do Estado conforme a linha teórica do governo que estiver no poder.

Nesse aspecto, é importante compreender a diferença entre Estado e governo. A respeito, Höfling (2001) enfatiza o

Estado como o conjunto de instituições permanentes - como órgãos legislativos, tribunais, exército e outras que não formam um bloco monolítico necessariamente - que possibilitam a ação do governo; e Governo, como o conjunto de programas e projetos que parte da sociedade (políticos, técnicos, organismos da sociedade civil e outros) propõe para a sociedade como um todo, configurando-se a orientação política de um determinado governo que assume e desempenha as funções de Estado por um determinado período (p. 31).

Com base no que a autora apresenta, o Estado está solidificado na sociedade; ademais, representa o interesse de diferentes grupos sociais, principalmente dos setores econômicos. Verifica-se, portanto, que o governo é transitório, representado por um partido que tem a oportunidade de imprimir seus programas e projetos na condução do Estado. Nessa perspectiva, as concepções se modificam de acordo com a alternância de poder, o que se reflete na condução e elaboração das políticas sociais.

Para tanto, o Estado é demarcado por contradições sociais, culturais, políticas e econômicas. o governo que detém o poder, porém, busca reduzir estas contradições - que podem ser questionáveis - por meio das políticas sociais, principalmente para combater as desigualdades sociais. Para Höfling (ibidem), as

Políticas sociais se referem a ações que determinam o padrão de proteção social implementado pelo Estado, voltadas, em princípio, para a redistribuição dos benefícios sociais visando à diminuição das desigualdades estruturais produzidas pelo desenvolvimento socioeconômico.

As análises da autora reforçam os aspectos contraditórios do Estado, promovidos pelo modelo de desenvolvimento econômico. Entretanto, as políticas educacionais têm a função de reduzir os impactos negativos que atingem os setores menos favorecidos da sociedade. Höfling (ibidem) reforça que a educação é "uma 
política pública social, uma política pública de corte social, de responsabilidade do Estado - mas não pensada somente por seus organismos".

Por essa lógica, é compreensível o debate que a classe trabalhadora tem pautado sobre a importância das políticas educacionais serem construídas com a participação social. O Estado, porém, tem a prerrogativa da implementação, cabendo à classe trabalhadora promover o debate sobre suas finalidades.

Não obstante, tem-se questionado a forma como o Estado tem primado pela formulação das políticas públicas, uma vez que, na maioria das vezes, as decisões se dão de forma centralizada. Com isso, não são levadas em consideração os aspectos regionais, com suas especificidades, gerados no processo de implementação. Frente a isso, há uma luta constante para que tais perspectivas sejam modificadas no processo de elaboração das políticas educacionais.

Caso o Estado considerasse essa perspectiva, teria a possibilidade de identificar os condicionantes locais na implementação das políticas; contudo, tem sido intransigente ao propor este debate. Tais posições têm em vista a manutenção das relações de poder político na sociedade. A esse respeito, Höfling (2001) pontua que

\footnotetext{
As políticas sociais - e a educação - se situam no interior de um tipo particular de Estado. São formas de interferência do Estado, visando à manutenção das relações sociais de determinada formação social. Portanto, assumem "feições" diferentes em diferentes sociedades e diferentes concepções de Estado. É impossível pensar Estado fora de um projeto político e de uma teoria social para a sociedade como um todo (p. 31-32).
}

No entendimento da autora, a educação se reproduz conforme as concepções e ideologias do Estado. Por sua vez, como predominam os interesses capitalistas nos direcionamentos das ações estatais, as políticas educacionais não estão imunes a este processo. Mesmo que o poder político do Estado seja assumido por governos de diferentes vertentes ideológicas, a essência das políticas se mantém, uma vez que não rompem com a lógica do capital (MÉSZÁROS, 2011).

O Estado capitalista atua como guardião dos direitos dos cidadãos, porém, em função da manutenção dos seus poderes; ou seja, é mais com a intenção de promover a dominação do que de conferir autonomia aos sujeitos. Nessa perspectiva, as políticas sociais são implementadas como forma de regular os conflitos sociais.

A este respeito, Höfling (Idem, p. 33) destaca que Offe em suas análises, chamava atenção para o fato de o Estado atuar "como regulador das relações sociais a serviço da manutenção das relações capitalista em seu conjunto, e não 
especificamente a serviço dos interesses do capital". Assim sendo, as diferentes feições que as políticas educacionais assumem está em plena sintonia com a ideologia do Estado.

Notadamente no campo do discurso, a educação está sempre em evidência na agenda governamental como estratégia fundamental, seja em relação ao aspecto econômico ou como indutora do desenvolvimento e no combate às desigualdades sociais. Essas duas perspectivas são apontadas por Oliveira e Ferreira (2008) como as principais funções que assume a política econômica de um país para conter a pobreza. Evidencia-se, portanto, que, no Estado capitalista, a educação tem bem definido seu papel.

Tais estratégias passaram a ser bem mais definidas a partir dos anos de 1990 com a reforma do Estado. Para Oliveira e Ferreira (2008), foi o momento em que houve um movimento articulado de expansão e focalização das políticas educacionais. Os redirecionamentos que houve foram pensados levando-se em conta uma racionalidade que visou a sopesar os custos e benefícios dos investimentos dos recursos públicos. Para esses autores,

Ao mesmo tempo em que se ampliam políticas, em alguns casos, estendendo o atendimento, focaliza-se o público-alvo, ou seja, estamos diante de um processo em que as políticas sociais de caráter universal têm cedido espaço às políticas de cunho compensatório. Esse aparente paradoxo, que tem gerado polêmicas entre os educadores e diferentes compreensões dos processos de reformas educacionais atuais, reflete contradições próprias desse movimento que aprofunda e fragmenta os movimentos sociais ( p. 24).

Como se verifica, as políticas não são formuladas para atender toda a população, mas um público específico, com o propósito de amenizar determinados impactos sociais. Isso evidencia seu caráter reducionista e compensatório, como bem destacaram as autoras. Essa tese reforça o pensamento do Estado mínimo para as políticas sociais e máximo para o capital. É nesta perspectiva que Dourado (2001) pontua que o mercado assume o papel de portador da racionalização sociopolítica conservadora ao primar pela minimização do papel do Estado no tocante às políticas públicas.

Depreende-se que essa lógica tem servido de orientação para a elaboração das políticas educacionais, o que tem gerado muitas críticas entre os educadores e os movimentos em defesa da escola pública. Com as reformas do Estado dos anos de 1990, principalmente nos governos de Fernando Henrique Cardoso (1995/1998 e 1999/2002), as disputas pelas definições das políticas passaram a ter novos sujeitos, além das organizações sociais que vinham debatendo estes processos. 
O setor privado passou a exercer grandes influências nos direcionamentos das políticas educacionais. Para esses novos sujeitos, o Estado deveria ser mais eficiente em suas ações; com isso, a função pública assumiu novos contornos como normalizadora, reguladora e avaliadora (OLIVEIRA; FERREIRA, 2008).

Esses princípios se refletem na criação dos vários instrumentos de avaliação do sistema de ensino brasileiro, com destaque para a implantação do Censo Escolar, do Sistema de Avaliação da Educação Básica (SAEB), do Exame Nacional do Ensino Médio (ENEM) e do Exame Nacional de Cursos (Provão) (SHIROMA, 2000).

Atualmente, ainda há o Índice de Desenvolvimento da Educação Básica (IDEB). Assim sendo, são os principais mecanismos utilizados na estratégia de regular e aferir a qualidade da educação, na perspectiva do Estado. Há uma grande preocupação com os dados quantitativos em detrimento do qualitativo. Portanto, a educação, com base nas reformas, realinhou-se às estratégias das políticas de cunho compensatório.

O Estado consolidou esses novos reordenamentos a fim de atender à demanda do capital em detrimento dos direitos sociais da população. Isso se evidencia por meio da nova lei que passou a regulamentar a educação, a LDB 9394 (BRASIL, 1996) e a proposta de financiamento da educação por meio da política de fundos, iniciada com o FUNDEF e. posteriormente, substituída pelo FUNDEB. Essas iniciativas deram à sociedade o tom que, de fato, estava havendo uma mudança estrutural nas políticas educacionais.

A esse respeito, Oliveira e Ferreira (2008) destacam que

\footnotetext{
A reforma educacional concentrou-se no primeiro mandato de FHC e atingiu, especialmente, o Ensino Fundamental por meio de políticas de financiamento e planejamento, como a instauração do Fundo de Desenvolvimento e Manutenção do Ensino Fundamental e Valorização do Magistério (Fundef), criado pela Lei n $9.425 / 96$, e a promulgação da Educação Nacional (LDBEN), Lei nº 9394/96. Foi se consolidando um sistema nacional de avaliação que abrangeu todos os níveis de educação do país; além do estabelecimento dos Parâmetros Curriculares Nacionais (PCNs) (p. 37).
}

Esse conjunto de políticas, orquestrado pelo Estado, representou as principais estratégias que consolidaram a reforma da educação e que serviram para materializar a concepção de um governo que estava alinhado às ideologias das políticas neoliberais. Essas decisões foram justificadas sob o argumento de que era necessário tornar o Estado mais moderno, eficiente e, ao mesmo tempo, garantir que as políticas educacionais respondessem aos aspectos econômicos e sociais do país. Destarte, as políticas atenderam à nova função pública de um Estado normalizador, regulador e avaliador. 
No entanto, há muitas contradições na elaboração e implementação das políticas, como é caso do financiamento da educação. Para o governo, a política de fundos (FUNDEF/FUNDEB) para financiar o Ensino Fundamental e, posteriormente, a Educação Básica, representaria mais recursos para a educação. Todavia, na prática, configurou-se mais como um jogo contábil do que propriamente novas fontes de recursos para a educação. Isso porque o fundo apenas centralizou a capitalização dos impostos destinados à educação da União, Estados e municípios, fazendo com que houvesse a redistribuição com base no número de matrículas dos sistemas de ensino.

Concretamente, tanto o FUNDEF quanto o FUNDEB não significaram novas fontes de financiamento, uma vez que mantiveram os mesmos percentuais de aplicação na educação, conforme orienta a Constituição Federal de 1988: o mínimo de $25 \%$ da receita para Estados e municípios e, para a União, 18\%. Para Ramos e Di Giorgi (2011),

A União ficou com as funções redistributiva e supletiva na manutenção e no desenvolvimento do Ensino Fundamental, ou seja, a União completaria os recursos financeiros dos estados cujo custo-aluno ficasse abaixo do custo-aluno mínimo definido nacionalmente (p. 629-630).

Levando em conta este exemplo do FUNDEF, observa-se como o Estado brasileiro se posicionou no controle das políticas, uma vez que passou a centralizar os recursos da educação, cabendo a estados e municípios apenas a aplicação. Na perspectiva do governo, os recursos da educação eram suficientes, necessitando apenas uma distribuição mais equitativa entre os entes federados. França (2007) contribui para esse entendimento ao destacar que

O FUNDEF, oriundo de uma política pública formulada pelo governo federal, pretendia corrigir a má distribuição de recursos entre as diversas regiões e diminuir as desigualdades presentes na rede pública de ensino, promovendo uma política nacional de equidade, justiça social, melhoria da qualidade da educação e valorização do magistério, além da efetiva descentralização dos recursos para as redes estaduais e municipais de ensino. (p. 184).

Esta lógica reforça a opção de um Estado mínimo para o atendimento das políticas sociais ao priorizar resolver os problemas da educação com os mesmos percentuais de investimento definidos em 1998 pela Constituição Federal. Isso denota que os princípios e fundamentos das políticas educacionais, nos ano de 1990, estavam alinhados às ideologias neoliberais em detrimento dos interesses da classe trabalhadora.

O Estado, fundamentado em uma ideologia modernista e reformista, não 
possibilitou ao conjunto da sociedade um debate franco para a construção de políticas públicas educacionais. Preferiu alinhar-se aos interesses neoliberais. Em relação a esses aspectos, Boneti (2011) destaca que

\footnotetext{
Cada momento histórico produz, no contexto da inter-relação entre a produção econômica, cultura e interesses dos grupos dominantes, ideologias a partir das quais verdades relativas tornam-se absolutas. Estas verdades absolutas, construídas ideologicamente em cada formação social, produzem e referenciam as ações institucionais e, em particular, a elaboração e a operacionalização das políticas públicas (p. 11).
}

As considerações de Boneti contribuem para compreender o momento econômico do país nos anos de 1990. Os países periféricos vinham sofrendo fortes pressões para o ajuste econômico e administrativo a fim de reduzirem os custos sociais do Estado e, ao mesmo tempo, abrirem suas economias para o capital. A partir do governo de FHC, no ano de 1995, iniciou-se a materialização dessas ideologias neoliberais que levou à reestruturação do Estado brasileiro, conforme as orientações dos organismos internacionais, tais como o FMI e o Banco Mundial.

De acordo com Soares (2003),

O Banco Mundial passou a impor uma série de condicionalidades para a concessão de novos empréstimos. [...] passou a intervir diretamente na formulação da política interna e a influenciar na própria legislação dos países. [...] passou a exercer amplo controle sobre o conjunto das políticas domésticas, sendo peça chave no processo de reestruturação desses países [...] reforçou a sua capacidade de impor políticas, dado que, sem o seu aval e do FMI, todas as fontes de crédito internacional são fechadas, o que torna muito difícil a resistência de governos eventualmente insatisfeitos com a nova ordem (p. 21).

Para a autora, em detrimento dos interesses que o Brasil tinha para aquisição de novos empréstimos para investir nas áreas de energia, transporte, educação entre outras áreas, não havia alternativa a não ser seguir as orientações do Banco Mundial e do FMI. Assim, o ajuste na economia, iniciado a partir dos anos de 1990, era a contrapartida do estado brasileiro para acessar os empréstimos dos organismos internacionais. O interesse do governo era criar infraestrutura para favorecer a instalação do capital financeiro no país.

\section{DESAFIOS E CONTRADIÇÕES DAS POLÍTICAS EDUCACIONAIS PARA A AMAZÔNIA}

Discutir a construção de políticas públicas no Estado, partindo do local, 
é romper com lógica da centralização e concentração, que ainda permanece, principalmente no campo da educação na qual as definições se dão no governo central, cabendo aos estados e municípios a execução..

Mesmo que haja um ou outro ente federado que tenha programas e projetos específicos elaborados por seus respectivos governos, estes não podem, no campo da legislação, definir leis que se sobreponham à LDB. Como destacado anteriormente, o governo federal centraliza também a capitalização dos principais recursos da educação para efetivar a distribuição. Assim sendo, estados e municípios gozam de autonomia relativa. Contraditoriamente, o Brasil, país continental com múltiplas diferenças sociais, econômicas, culturais e geográficas, tem suas políticas estruturadas ainda de forma centralizada, com base numa visão de homogeneidade.

Diante disso, há a necessidade de se pensarem as especificidades das políticas educacionais para a Amazônia, uma vez que suas dinâmicas geográficas demandam um olhar diferenciado. A este respeito, Cavalcante e Weige (2015) destacam que

Do ponto de vista de sua composição cultural, a população amazônica é caracterizada por uma rica sociodiversidade. Existem na região cerca de $200 \mathrm{mil}$ índios, constituindo 81 etnias diferentes, em pleno domínio e uso de suas línguas e culturas específicas. Além disso, culturas caboclas, vividas por grupos ribeirinhos que habitam o interior, às margens de rios, lagos e igarapés constituem também modos de vida amazônicos representando experiências e conhecimentos sobre formas de coexistência e utilização do meio local (p. 2).

Suas características populacionais, geográficas e culturais evidenciam por si só a necessidade de políticas que levem em consideração esses aspectos. Principalmente as populações ribeirinhas dispersas às margens de dezenas de rios, furos e igarapés, pois essas têm o direito de serem atendidas por políticas educacionais que respeitem suas dinâmicas organizacionais e de vida. Porém, a constituição das políticas se distancia de suas realidades, muito por conta de uma concepção de mundo consolidada com base nos povos considerados desenvolvidos. A este respeito, Boneti (2011) destaca que

Existe a tendência de alguns povos, sobretudo os considerados desenvolvidos, de adotarem o entendimento segundo o qual as suas sociedades centralizam a verdade em termos de costumes culturais, desenvolvimento social e econômico, etc. Estas sociedades têm dificuldade de compreender como verdade as diferenças culturais que não sejam as suas (BONETI, 2011, p. 23).

O que o autor apresenta é o retrato da forma como as políticas educacionais são concebidas para o atendimento das populações amazônicas, na 
qual as peculiaridades e diferenças culturais não são levadas em consideração. A lógica de considerar como verdadeiros os conhecimentos produzidos no centro tem exercido fortes influências na elaboração das políticas.

Essas concepções se refletem em certa imposição pelo Estado na forma de organização das escolas do campo no território da Amazônia. Neste aspecto, encontram-se escolas multisseriadas, que, embora estejam presentes em todos os sistemas de ensinos dos Estados da federação, têm predominância nas regiões norte e nordeste do país. Por conseguinte, garantem a escolarização a milhares de alunos do campo nessas regiões. Contraditoriamente, porém, o Estado insiste em buscar formas de eliminá-las.

Para os gestores, elas devem ser eliminadas em função de um ensino precário que ofertam e também por funcionarem em espaço que não oferece as mínimas condições estruturais de atendimento educacional. Diante disso, ao invés de o Estado propor políticas para a mudança desse quadro e adotá-las como forma específica de organização e oferta do ensino às populações do campo, prefere substituí-las por outras formas de organização do ensino, com custos muito mais elevados.

A precarização do ensino nas escolas multisseriadas é promovida pela negligência do próprio poder público, uma vez que é o principal agente de implementação das políticas educacionais. Para o Estado, as escolas multisseriadas são problema, ao invés de ser a solução da oferta do ensino às populações do campo na Amazônia em função da dispersão geográfica em que vivem.

Nos últimos anos, a forma que o Estado encontrou para eliminar as escolas multisseriadas no campo foi apoiar os municípios para realizarem a nucleação. $\mathrm{O}$ Instituto Nacional de Estudos e Pesquisas Educacionais Anísio Teixeira (INEP) (BOF, 2006) classifica a nucleação como "procedimento político-administrativo que consiste na reunião de várias escolas isoladas em uma só, desativando ou demolindo as demais" (p. 116). Esse procedimento consiste na construção das escolas núcleos com maior número de salas e mais estrutura pedagógica para a implantação da seriação.

Nessa perspectiva, o transporte escolar é fundamental para garantir o deslocamento dos alunos às escolas núcleos, que, por sua vez, contam com apoio financeiro do MEC por meio do Fundo Nacional de Desenvolvimento da Educação (FNDE). Portanto, o transporte escolar surgiu com a finalidade de dar suporte à nucleação. Porém, essa política direcionada para a Amazônia tem suas contradições, pois, pensar o modelo seriado como o mais adequado às comunidades do campo é cair na lógica da homogeneidade das políticas, como destacado por Boneti (2011). 
É importante salientar que a existência das escolas multisseriadas no campo brasileiro, em especial na Amazônia, tem mais a ver com os aspectos demográficos da organização populacional das comunidades do que com uma mera opção de criar essas turmas. A título de exemplo, numa comunidade em que existam 20 crianças com idade escolar diferente, o Estado não pode se eximir de ofertar a educação a esses sujeitos pelo fato de não ser possível criar turmas por série.

Esse é o contexto de muitas comunidades e localidades espalhadas pela Amazônia. Portanto, as escolas multisseriadas são a formar de garantir o direito à educação dessas populações. São políticas efetivadas na região amazônica, nas quais as características de organização das populações são ignoradas, assim como suas diferenças e aspectos culturais próprios. Segundo essa lógica de pensar as políticas, chamada por Boneti (2011) de etnocentrismo,

\begin{abstract}
Existe uma verdade única e universal, entendida como o centro, é a partir dela que se constituem as atribuições de certo e do errado. O etnocentrismo tem origem justamente na razão científica, do entendimento que a ciência é única e universal, que a verdade científica guarda requisitos universais que a distinguem como ciência. É deste pensamento que nasce a concepção de dualidade envolvendo a ideia de centro e periferia como atribuição do valor de verdade. $\mathrm{O}$ centro retém mais e melhor tecnologia, mais riquezas e mais verdade. Com isso, nasce a tendência de se atribuir modelos sociais, culturais e de desenvolvimento social. A partir desta concepção, as necessidades dos grupos dominantes são absorvidas pelas sociedades consideradas pobres como suas, assim como a superação das carências da população pobre feita utilizando-se das estratégias dos grupos dominantes. (p. 23).
\end{abstract}

Para o autor, esses princípios do etnocentrismo têm orientado as decisões do Estado na definição das políticas públicas. Assim, a substituição das escolas multisseriadas pelas seriadas com a constituição das escolas núcleos, obedeceria essa lógica de organização do ensino como a mais apropriada para a oferta da educação às populações do campo.

É preciso superar essa concepção de estruturar as políticas públicas. Assim, dialogar com as populações pode ser um caminho promissor, a fim de reduzir as contradições. As políticas, para que sejam inclusivas e alcancem maiores êxitos, devem ser constituídas partindo da heterogeneidade populacional, principalmente, na Amazônia. Por conseguinte, não se deve renunciar aos conhecimentos científicos, porém, estes não devem ser predominantes, uma vez que os saberes sociais também são importantes. Não é admissível que apenas os interesses dos grupos dominantes prevaleçam na definição das políticas públicas em detrimento da classe trabalhadora. 


\section{ALGUMAS IMPRESSÕES}

As análises apresentadas sobre os princípios e fundamentos das políticas públicas evidenciam as contradições em sua elaboração e implementação, uma vez que têm sido estruturadas pelo Estado sem amplo diálogo com as organizações sociais que defendem a educação. Aliado a isso, há o fato de os recursos serem insuficientes diante da demanda da universalização do ensino. Entretanto, cria-se um discurso ilusório de que são suficientes, necessitando apenas eficiência em sua aplicação.

As políticas educacionais elaboradas sob a vertente do Estado capitalista têm ignorado a participação da sociedade; com isso, predominam os interesses dos governos que estão no poder. Nessa perspectiva, prevalece o caráter da homogeneidade na concepção das políticas em detrimento da heterogeneidade, como é caso da Amazônia. Nesse aspecto, as escolas multisseriadas são um problema na estrutura educacional dos sistemas de ensino para os governos.

Entretanto, contraditoriamente, para as populações do campo são uma forma de garantir a educação nos locais em que residem. Nesse contexto, o desafio é o Estado reconhecer essas especificidades a fim de estruturar políticas educacionais elaboradas de forma contextualizada.

\section{REFERÊNCIAS}

BOF, Alvana Maria (org.); SAMPAIO, Carlos Eduardo Moreno et al.. A educação no Brasil rural. Braślia: Instituto Nacional de Estudos e Pesquisas Educacionais Anísio Teixeira (INEP), 2006 Disponível em <www.inep.gov.br/ imprensa/noticias/outras/news06_13.htm>.

BONETI, Lindomar Wessler. Políticas públicas por dentro. 3. ed.. Ijuí: Ed Unijuí, 2011.

BRASIL Lei 9394 de 20 de dezembro de 1996. Estabelece as diretrizes e bases da educação nacional. Brasília: Imprensa Nacional, 1996.

CARDOSO, Maria Angélica. A organização do trabalho didático nas escolas isoladas paulistas: 1893 a 1932. 2013, Tese (Doutorado em Educação) Universidade Estadual de Campinas. 2013. 
CAVALCANTE, Lucíola Inês Pessoa; WEIGE, Valéria Augusta C. de M. Educação na Amazônia: oportunidades e desafios. Disponível em < http:// www.desenvolvimento.gov.br/arquivo/secex/sti/indbrasopodesafios/coletanea/ ofutamazonia/04LuciolaInes.pdf>. Acesso em 23/10/2015.

DOURADO, Luiz Fernandes. A reforma do Estado e as políticas de formação de professores nos anos 1990. In: PARO, Vitor Henrique; DOURADO, Luiz Fernandes (Orgs). Políticas Públicas \& educação básica. - São Paulo: Xamã, 2001.

FRANÇA, Magna. O financiamento da Educação Básica: do Fundef os Fundeb. In: QUEIROZ, Maria Aparecida de (Orgs) et al. Pontos e Contrapontos da política educacional: uma leitura contextualizada de iniciativas governamentais. - Brasília: Líber Livro Editora, 2007.

HÖFLING, Eloisa de Mattos. Estado e políticas (públicas) sociais. Cadernos Cedes, ano XXI, n ${ }^{\circ}$ 55, novembro/2001, P. 30-41

MÉSZÁROS, István. Para além do Capital: rumo a uma teoria da transição. Trad. Paulo Cezar Castanheira e Sérgio Lessa. 1ª ed. Revista. São Paulo: Boitempo, 2011.

OLIVEIRA, Dalila; FERREIRA, Elisa. Políticas sociais e democratização da educação: novas fronteiras entre público e privado. In: AZEVEDO, Mário Luiz (org.). Políticas públicas: debates contemporâneos e educação. Maringá: Eduem, 2008.

RAMOS, Regina Celia, DI GIORGI, Cristiano Amaral. Do Fundef ao Fundeb: avaliando o passado para pensar o futuro: um estudo de caso no município de Pirapozinho-SP. Ensaio: aval. pol. públ. Educ., Rio de Janeiro, v. 19, n. 72, p. 623-650, jul./set. 2011

SHIROMA, Eneida Otto. et al (org). Política Educacional. Rio de Janeiro: DP\&A editora, 2000.

SOARES, Maria Clara Couto. Banco Mundial: políticas e reformas. In: DE TOMMASI, Lívia; WARDE, Mirian Jorge; HADDAD, Sérgio (Org). O Banco Mundial e as políticas educacionais. 4. ed. São Paulo: Cortez, 2003. 
ERALDO SOUZA CARMO é doutorando em educação. Professor Assistente I da Faculdade de Educação - Campus Universitário do Tocantins - Cametá UFPA. Atua na linha de pesquisa educação do campo, financiamento e política educacionais. E-mail: eraldo@ufpa.br

MARIA SUELI CORRÊA PRAZERES é Pedagoga, Especialista em Informática na educação e Mestre em Educação pela Universidade Federal do Pará (2008). Atualmente é Professora Assistente da Universidade Federal do Pará. Cursa Doutorado em Educação pela Universidade Estadual de Ponta Grossa/PR. E-mail: suelicorrea@ufpa.br

Recebido em novembro de 2015

Aprovado em dezembro de 2015 